\title{
WIND POWER PLANT WITH SYNCHRONOUS-ASYNCHRONOUS GENERATOR
}

\author{
Gennady Nikitenko $^{1}$, Evgeny Konoplev ${ }^{1}$, Anatoly Permyakov ${ }^{2}$, Andrey Bobryshev ${ }^{1}$ \\ ${ }^{1}$ Stavropol State Agrarian University, Russia; ${ }^{2}$ Yaroslav-the-Wise Novgorod State University, Russia \\ nikitenko_gv@mail.ru, konoplev82@mail.ru
}

\begin{abstract}
The article considers a propeller-type wind power plant, which uses an asynchronous generator with a short-circuited rotor and a synchronous reversible machine as a generating system. The synchronous machine is connected on one side to the shaft of the wind turbine, on the other side to the rotor of the asynchronous generator. The synchronous machine contains permanent neodymium magnets and a magnetic wire located on the outer and inner rings of the rotor. This solution allows to increase the power and energy efficiency of the synchronous machine. With an excess of wind load, the synchronous machine operates in generator mode and accumulates electricity in the batteries, thereby providing additional braking torque on the wind turbine shaft and achieving stabilization of the rotation speed of the rotor of the asynchronous generator, as a result, voltage stabilization at its phases. If there is a lack of wind load, the synchronous machine operates in the motor mode using the energy stored in the batteries, which allows to stabilize the rotor speed of the asynchronous generator and the voltage at its phases when the wind changes. Power supply to consumers is carried out from an asynchronous generator, voltage stabilization at the phases of the asynchronous generator, when the wind load and power of consumers change, by changing the operating mode of the synchronous machine. The power of the asynchronous generator is $1.1 \mathrm{~kW}$ at a nominal speed of 1100 , the power of the synchronous machine is $1.2 \mathrm{~kW}$. A block diagram of a wind power plant is presented, on the basis of which an electromechanical scheme of the plant is constructed. The article presents a mathematical model of its operation developed on the basis of an electromechanical scheme of a wind power plant, presents the results of mathematical modeling and makes the main conclusions and suggestions.
\end{abstract}

Keywords: wind power, asynchronous generator, synchronous generator, power supply.

\section{Introduction}

The development of agricultural facilities that are remote from centralized power supply systems, the high cost and the constant increase in prices for traditional energy sources make the use of alternative energy sources, such as wind, the most acceptable option for autonomous power supply to consumers.

Autonomous power supply systems based on a wind power plant in modern conditions should provide energy to both single-phase and three-phase consumers. According to the criteria of reliability, maintainability, cost and prevalence in agriculture, an asynchronous generator with a short-circuited rotor is best suited for these requirements. However, the use of an asynchronous generator in a wind power plant is associated with the problem of stabilizing the rotation speed of the rotor and, as a result, the voltage at its phases, when the wind load and the power of electric energy consumers change. Moreover, it should be noted that the critical dependence of the voltage in the phases of an asynchronous generator with a short-circuited rotor on the rotor speed, which after its excitation is $\pm 2-5 \%$ of the nominal values of the rotor speed, in which the voltage deviation requirement is maintained [1-6].

The use of an asynchronous generator with a short-circuited rotor as part of a wind power plant is due to its high reliability, durability, maintainability and low cost, which directly affects the duration of operation of the autonomous power supply system, the cost of electricity generated and the cost of the wind power plant as a whole.

Thus, for the use of an asynchronous generator with a short-circuited rotor in a wind power plant, it is necessary to use a device for stabilizing the rotation of the generator rotor, which is proposed to use a reversible synchronous machine with a double-circuit magnetic system with increased energy characteristics.

\section{Materials and methods}

The diagram of a wind power plant is proposed is shown in Figure 1. The wind power plant works as follows. With an excess of wind load, the torque from the wind turbine shaft through the overrunning clutch enters the rotor of the synchronous machine, which rotates freely relative to the stationary stator of the synchronous machine. The rotor of the synchronous machine is divided into two rings, external and internal, on which the magnetic core with permanent magnets and pseudo poles are located. This solution allows to increase the power of a synchronous machine by 4 times compared to a single-circuit magnetic rotor system. IN more detail, the design and principle of operation of a synchronous machine 
with increased energy characteristics are discussed in the article $[7 ; 8]$. The resulting torque from the wind wheel and the torque generated by the synchronous machine is fed to the rotor of the asynchronous generator. A battery of starting capacitors is used to excite the asynchronous generator, the energy from which is supplied to the consumer.

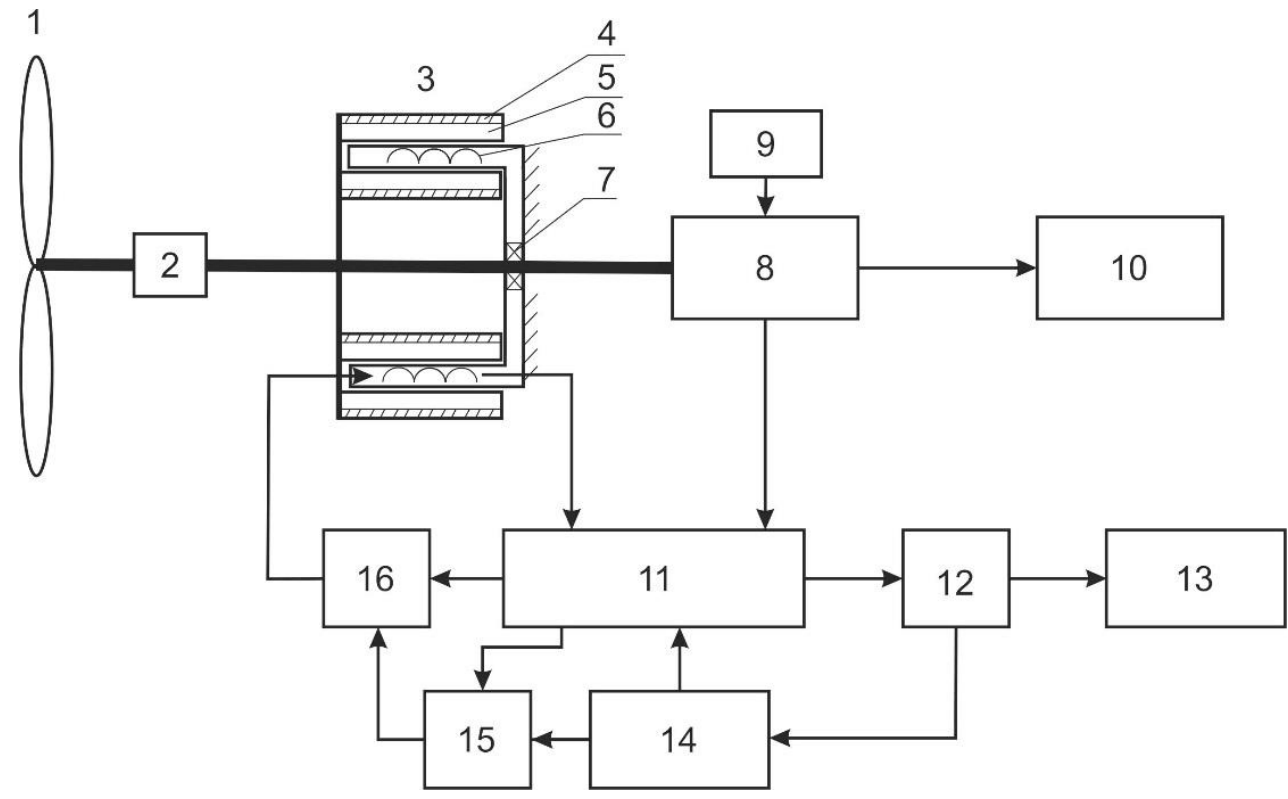

Fig. 1. Combined scheme of a wind power plant: 1 - wind turbine; 2 - overrunning clutch; 3 - synchronous machine; 4 - magnetic circuit; 5 - permanent magnets; 6 -stator winding of a synchronous machine; 7 - bearing; 8 - asynchronous generator with a short-circuited rotor;

9 - battery of starting capacitors; 10 - load; 11 - control system; 12 - charge controller;

13 - ballast load; 14 - battery; 15 - inverter; 16 - switching unit

The synchronous machine can work in the motor and generator mode, when working in the generator mode, the excess energy coming from the wind turbine is converted by the synchronous machine into electricity and through the control system, the charge controller and accumulated in the battery. When the battery is fully charged, the electric power from the synchronous machine is transferred to the ballast load. In this case, the synchronous machine creates an additional braking torque, thereby stabilizing the rotation speed of the rotor of the asynchronous generator and, as a result, the voltage at its phases with an excess of wind load.

In the event of a lack of wind load, the synchronous machine operates in the motor mode, using the energy stored in the battery, through the inverter and the switching unit the voltage is applied to the stator windings of the synchronous machine, and the level of voltage and current supplied to the stator winding of the synchronous machine is formed by the control system depending on the voltage at the stator phases of the asynchronous generator.

Figure 2 shows an electromechanical diagram of a wind power plant.

Based on the electromechanical scheme of a wind power plant, the balance of mechanical torque can be determined from the expression (1), while in the steady-state mode their algebraic sum is zero.

$$
M_{V} \pm M_{S M}-M_{A G}=0,
$$

where $M_{V}-$ torque on the wind turbine shaft, $\mathrm{N} \cdot \mathrm{m}$;

$M_{S M}$ - synchronous machine torque, $\mathrm{N} \cdot \mathrm{m}$;

$M_{A G}$ - torque of the asynchronous generator, $\mathrm{N} \cdot \mathrm{m}$.

The power of a synchronous machine is determined by the expression (2).

$$
P_{S M}=M_{\mathrm{SM}} \omega_{\mathrm{SM}}=U_{s m} I_{s m} \eta_{s m} \cos \varphi_{s m},
$$

where $\omega_{\mathrm{SM}}-$ angular velocity of the synchronous machine rotor, $\mathrm{rad} \cdot \mathrm{s}^{-1}$;

$U_{s m}-$ stator voltage of the synchronous machine, $\mathrm{V}$;

$I_{s m}-$ stator current of the synchronous machine, A; 
$\eta_{s m}$ - efficiency of the synchronous machine;

$\cos \varphi_{s m}-$ power factor of the synchronous machine.

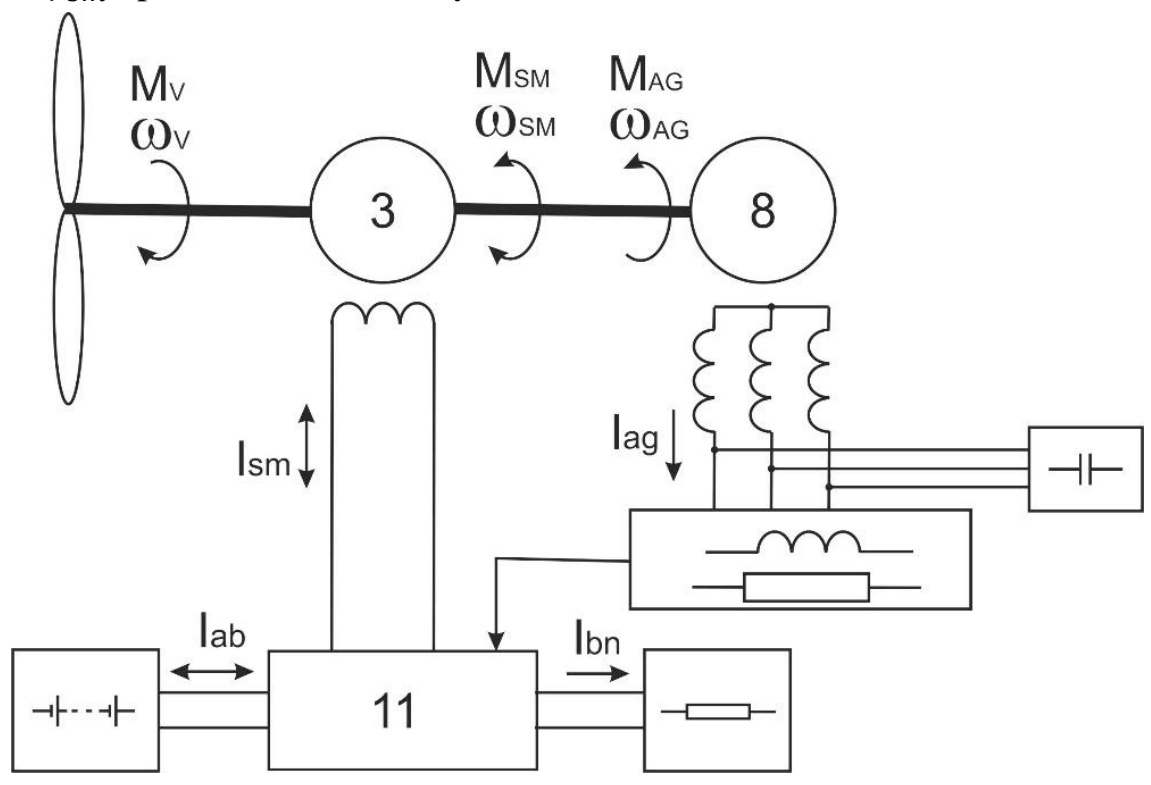

Fig. 2. Electromechanical circuit

The torque on the wind turbine shaft is defined as

$$
M_{V}=\frac{\pi R^{3}}{2 Z} \rho V^{2} C_{p}(V),
$$

where $R$-radius of the wind turbine, $\mathrm{m}$;

$Z$ - speed of the wind turbine;

$\rho$ - air density, $\mathrm{kg} \cdot \mathrm{m}^{-3}$;

$V$ - wind speed, $\mathrm{m} \cdot \mathrm{s}^{-1}$;

$C_{p}(V)$ - wind flow utilization factor of the wind turbine.

The speed of the wind turbine is determined by:

$$
Z=\frac{\omega R}{V},
$$

where $\omega$-angular velocity of the wind turbine rotor, $\mathrm{rad} \cdot \mathrm{s}^{-1}$.

The power of a three-phase asynchronous generator with a closed-loop rotor is defined as:

$$
P_{A G}=M_{\mathrm{AG}} \omega_{\mathrm{AG}}=\sqrt{3} U_{a g} I_{a g} \eta_{a g} \cos \varphi_{a g},
$$

where $\omega_{\mathrm{AG}}-$ angular velocity of the rotor of the asynchronous generator, $\mathrm{rad} \cdot \mathrm{s}^{-1}$;

$U_{a g}-$ voltage at the stator phases of the asynchronous generator, $\mathrm{V}$;

$I_{a g}-$ stator current of the asynchronous generator, A;

$\eta_{a g}-$ efficiency of the asynchronous generator;

$\cos \varphi_{a g}$ - power factor of the asynchronous generator.

Taking into account the expressions (1-5), we will express the parameter of interest - the voltage at the phases of the asynchronous generator:

$$
U_{a g}=\frac{0,5 \pi R^{2} \rho V^{3} C_{p}(V) \pm U_{s m} I_{s m} \eta_{s m} \cos \varphi_{s m}}{\sqrt{3} I_{a g} \eta_{a g} \cos \varphi_{a g}} .
$$

As it can be seen from the expression (6), the voltage at the phases of the asynchronous generator depends on the parameters of the wind turbine, wind speed and power of the synchronous machine operating in the motor or generator mode, as well as on the load current. Since the parameters of the voltage and current of the synchronous machine are interrelated, we represent from, as the power of the synchronous machine, we get: 


$$
U_{a g}=\frac{0,5 \pi R^{2} \rho V^{3} C_{p}(V) \pm P_{S M}}{\sqrt{3} I_{a g} \eta_{a g} \cos \varphi_{a g}} .
$$

Based on the obtained dependence (7) of the voltage at the phases of the asynchronous generator, depending on the system parameters, we will conduct mathematical modeling.

\section{Results and discussion}

Consider the case of a lack of wind load for the operation of an asynchronous generator. Let us take the following parameters: the radius of the wind turbine is 2.3 meters, the stator current of the asynchronous generator varies from 0.4 to $2.4 \mathrm{amps}$, the wind speed is $4 \mathrm{~m} \cdot \mathrm{s}^{-1}$, the power of the synchronous machine is $0.4,0.8$ and $1.2 \mathrm{~kW}$. In this case, the synchronous machine operates in the motor mode and, as it were, adds the missing power to the power developed on the wind turbine shaft, which leads to an increase in the voltage at the phases of the asynchronous generator.

The simulation results are shown in Figure 3.

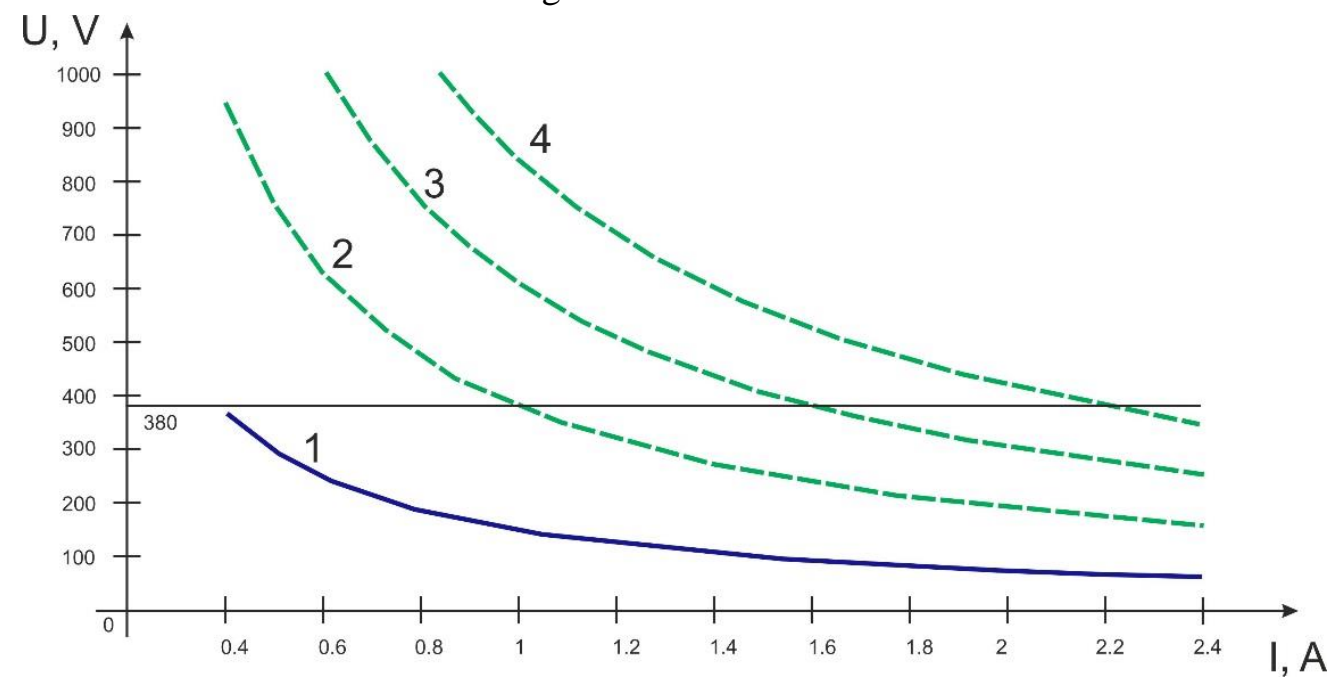

Fig. 3. Phase voltage of the asynchronous generator: 1 - operation from a wind turbine;

2 - operation from a wind turbine and a synchronous machine with a power of $0.4 \mathrm{~kW}$ in the motor mode; 3 - operation from a wind turbine and a synchronous machine with a power of $0.8 \mathrm{~kW}$ in the motor mode; 4 - operation from a wind turbine and a synchronous machine with a power of $1.2 \mathrm{~kW}$ in the motor mode

The phase voltage of the asynchronous generator at a wind speed of $4 \mathrm{~m} \cdot \mathrm{s}^{-1}$, depending on the load current, is represented by curve 1 , the value is less than $380 \mathrm{~V}$. To increase it, the synchronous machine works together in the motor mode and the asynchronous generator, which leads to an increase in the voltage at the generator phases to the required value.

As it can be seen from these graphs, with an increase in the power of a synchronous machine operating in the motor mode, the voltage at the phases of the asynchronous generator also increases. When the power of the synchronous machine in the motor mode is $1.2 \mathrm{~kW}$, the asynchronous generator produces a power of $1.4 \mathrm{~kW}$.

The voltage changes in the phases of the asynchronous generator with an excess of wind load are shown in Figure 4. The wind speed is assumed to be $8 \mathrm{~m} \cdot \mathrm{s}^{-1}$. The synchronous machine operates in generator mode, creating an additional braking torque on the wind turbine shaft.

To reduce the voltage at the phases of the asynchronous generator to $380 \mathrm{~V}$, the synchronous machine and the asynchronous generator work together in the generator mode. The synchronous machine creates an additional braking torque on the wind turbine shaft, which leads to a decrease in the transmission of torque to the rotor of the asynchronous generator, as a result of which the voltage at the phases of the asynchronous generator decreases.

From the graphs shown in Figure 4 it can be seen that with an increase in the power of a synchronous machine operating in generator mode, the voltage at the phases of the asynchronous generator decreases. 
By setting the power level of the synchronous machine by changing the voltage and current of its stator winding, voltage stabilization is achieved in the phases of the asynchronous generator when the wind load and the power of electric energy consumers change.

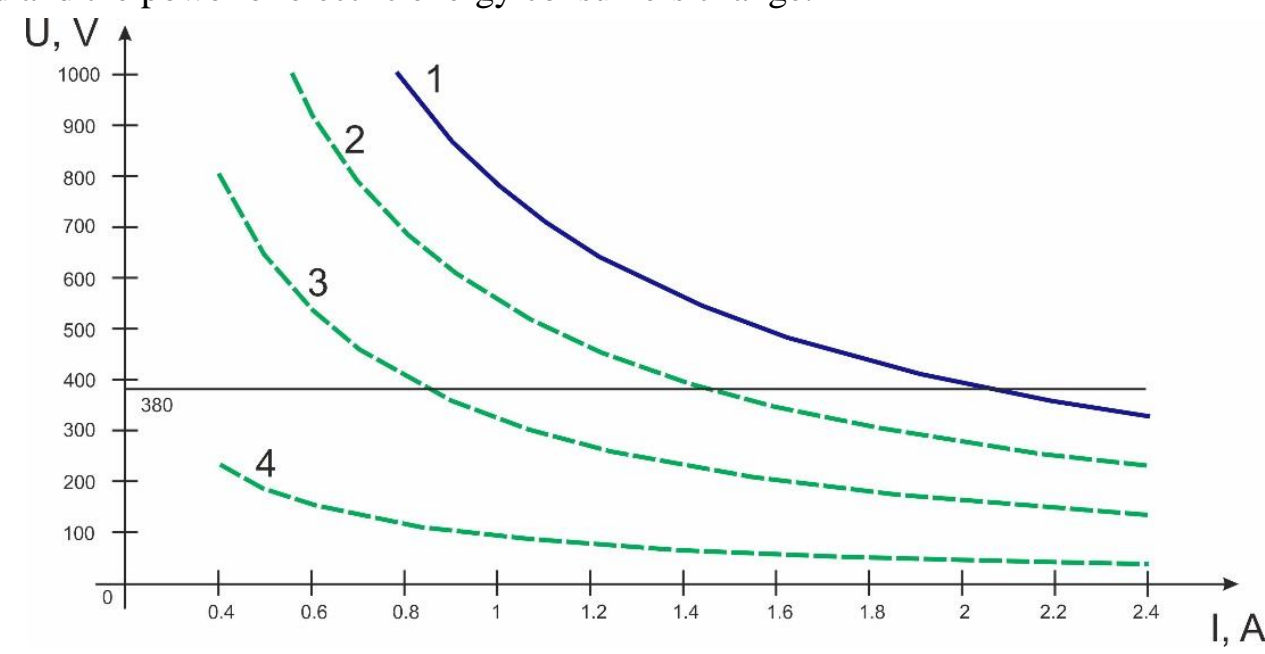

Fig. 4. Phase voltage of the asynchronous generator: 1 - operation from a wind turbine;

2 - operation from a wind turbine and a synchronous machine with a power of $0.4 \mathrm{~kW}$ in generator mode; 3 - operation from a wind turbine and a synchronous machine with a power of $0.8 \mathrm{~kW}$ in generator mode; 4 - operation from a wind turbine and a synchronous machine with a power of $1.2 \mathrm{~kW}$ in generator mode

\section{Conclusions}

1. The proposed block diagram of the wind power plant allows to get a three-phase stabilized voltage at the level of $380 \mathrm{~V}$ at a change in the wind load and power of consumers.

2. On the basis of a mathematical model of the operation of a wind power plant, graphical dependences of the voltage changes in the phases of an asynchronous generator with changes in the load power and wind speed are obtained, and the operation of a synchronous machine in the motor and generator modes is shown. From the obtained graphical dependences, it can be seen that the voltage stabilization at the phases of the asynchronous generator is possible, when the load current changes to $2.2 \mathrm{~A}$.

3. For an asynchronous generator with a power of $1.1 \mathrm{~kW}$, a synchronous machine with a power of $1.2 \mathrm{~kW}$ is adopted, which allows to stabilize the voltage on the stator of the asynchronous generator, when the wind speed changes from 0 to $25 \mathrm{~m} \cdot \mathrm{s}^{-1}$.

\section{References}

[1] Razmjoo A., Shirmohammadi R., Davarpanah A., Pourfayaz F., Aslani A. Stand-alone hybrid energy systems for remote area power generation. Energy Reports vol. 5, 2019. pp. 231-241.

[2] Samikannu R., Sampath Kumar V., Diarra B., Ravi R. Cost optimization and development of hybrid energy systems for rural areas in Ethiopia with a balance of their energy need and resources availability (a case study-on TulUDIMTU). Journal of Testing and Evaluation vol. 47(6), 2019, JTE20180462.

[3] Sun W., Harrison G.P. Wind-solar complementarity and effective use of distribution network capacity. Applied Energy vol. 247,2019, pp. 89-101.

[4] Al-Dousari A., Al-Nassar W., Al-Hemoud A., Al-Dousari N., Ahmed M. Solar and wind energy: Challenges and solutions in desert regions. Energy, vol. 176, 2019, pp. 184-194.

[5] Zhang X., Lu N., Jiang H., Yao L. Evaluation of Reanalysis Surface Incident Solar Radiation Data in China. Scientific Reports. 2020, 10(1), 3494.

[6] Shayeghi H., Hashemi Y. Potentiometric of the renewable hybrid system for electrification of gorgor station. 2020, Journal of Operation and Automation in Power Engineering 8(1), pp. 1-14.

[7] Nikitenko G., Konoplev E., Salpagarov V., Lysakov A. Solar and wind stand-alone power system. Engineering for Rural Development №18, 2019. pp. 1456-1462. 
[8] Pat. 2680642 Russian Federation, IPC H02K 1/27, H02K 21/12, H02K 16/02 Synchronous generator with dual magnetic system/Nikitenko G. V., Konoplev V. E., Salpagarov K. V., Konoplev P. V., Bobryshev A. V.; applicant and patent holder FGBOU IN Stavropol GAU. No. 2016152824; application. 30.12.16; publ. 25.01.18, Byul. No. 3. 